assess the effectiveness of doctoral outcomes.

\section{Challenges for Research}

Africa is viewed as a continent with huge potential for growth, and is called upon to harness its resources to emerge. Universities in Africa have tremendous capacities and resources to deploy in favor of training, development, and innovation. As the knowledge economy grows, careers needing doctoral education will emerge in Africa, and new methods of teaching and research will need to supersede the traditional ones. Academics holding a PhD must be motivated and guided to produce more doctorates that will strengthen and empower the labor force. Digitization and computerization will play a key role in the transformation process of all businesses, and of the financial, educational, and other key development sectors in Africa. Likewise, universities will need to provide increased access to electronic research databases and improved information technology

\section{CHET research further reveals that apart from UCT, the knowledge produc- tion and research output of the six flag- ship universities are not strong enough to make a sustainable contribution to development.}

facilities for conducting research. Universities will need to review their model of doctoral education for new and better models of postgraduate management, supervision and coordination, providing more peer interaction and international collaboration. Regulatory mechanisms and policies at national or regional level should guide the implementation of research strategies and plans. Regular assessments must be in place to ensure that the outcomes of doctoral education match skills requirement for the academic, industrial, public and private job markets. Tracer studies will certainly help to understand the degree of employability of the doctoral graduates on the job market, and will determine the extent of the research contribution and impact on the knowledge economy. Last but not least, increase in support must be provided for research performing institutions, with a more stable model for funding.

\section{Kyrgyzstan: Quality Assur- ance_-Do State Standards Matter?}

\section{Martha C. Merrill}

Martha C. Merrill is an associate professor of higher education administration at Kent State University, US. She wishes to thank IREX for a Short-Term Travel Grant that allowed her to do some of the research this article is based on. E-mail: mmerril@kent.edu.

$T$

The Kyrgyz Republic has been without a formal system for evaluating its higher education institutions since June 3, 20I4, when the Division of Licensing and Attestation in the Ministry of Education was abolished. Interestingly, neither students nor parents nor the media nor politicians seem to care very much. Roger King, in Governing Universities Globally (2009), has argued that higher education institutions are increasingly subject to both formal and informal regulation from a number of supranational sources, but that many variations are possible in the pathways from conception to implementation. Does the situation in Kyrgyzstan tell educators more about the influence of global governance or more about specific circumstances in Kyrgyzstan?

\section{Alternative Assessments}

Although Kyrgyzstan is not a member of the Bologna Process, it has been adopting Bologna reforms for several years, including switching from Soviet-era degrees to bachelor's and master's degrees. Another reform would be exchanging state attestation for independent accreditation, as required in the European Standards and Guidelines. When the Division of Licensing and Attestation was abolished, educators expected that independent accrediting agencies would be established quickly, but the Jogorku Kenesh (Parliament) has not yet approved the regulations needed to create them.

The fact that the Division of Licensing and Attestation was abolished does not mean that no ways of evaluating quality exist. Some higher education institutions, such as the Kyrgyz-Russian Slavonic University and the KyrgyzTurkish Manas University, were founded by intergovernmental agreements, and their diplomas are recognized in both countries. The American University in Central Asia has a dual-degree arrangement with Bard College, and students majoring in programs also offered by Bard can receive Bard diplomas.

Other universities are pursuing international accreditation for specific programs; the "German Informatik" program at the Kyrgyz State University of Construction, 
Transportation and Architecture, which has a partnership with the German Westsächsische Hochschule Zwickau, has been accredited by the German agency ASIIN, and business programs in at least two universities in the capital, Bishkek, are preparing for ACBSP (Accreditation Council for Business Schools and Programs) accreditation. The NGO EdNet, through a TEMPUS grant, has formed an accreditation agency, and, with European colleagues present for the site visits, has performed three pilot accreditations.

\section{Despite the fact that thousands of stu- dents could be denied diplomas in 2017 , little public concern is evident.}

\section{IMPLICATIONS}

In the system carried over from the Soviet era, a program had to be licensed before it could begin operating, and it went through attestation when it had its first group of graduates and every five years thereafter. If a program has not passed attestation, its graduates cannot receive state diplomas. Programs that were last attested in the 2009-2010 academic year should have undergone attestation in 20I420I5. In addition, since every comprehensive university in the country started new four-year bachelor's programs in 2012 , and the first graduates will complete those programs in 2017 , hundreds of new programs need either attestation or accreditation next spring.

Despite the fact that thousands of students could be denied diplomas in 20I7, little public concern is evident. One reason may be that Kyrgyzstan had parliamentary elections on October 4, 2015 and many decisions seem to be on hold until the results are known and a new government is formed. Another is that accreditation and attestation do not affect how current or incoming students pay for their educations. Those who score well on the National Scholarship Test, which is administered by the independent agency, the Center for Educational Assessment and Teaching Methods (CEATM), have their tuition paid by the state. Those who do not score well enough pay their own way. Additionally, state institutions are presumed to have the state behind them, and all institutions that award Kyrgyz diplomas have to follow the same curricula, so students (and parents) are not used to choosing universities based on curricular differences. Also, substantial consensus exists about the quality of the various newer and private universities, regardless of offi- cial program attestation. Moreover, as Alan DeYoung points out in his book, Lost in Transition (Information Age, 20II), many stakeholders are interested in higher education's latent functions, rather than its manifest ones: the government wants to keep the burgeoning youth population out of the stagnant job market; parents see "dat' detyam obrazovaniye"-give children education-as the socially correct thing to do; students see the chance to move to the capital or another city as attractive. The actual quality of the education does not matter much for any of these latent functions. Furthermore, in a relationship-based society, people often are "invited" to positions, and family connections may be more important than program quality for finding employment. Also, given the importance of family connections, many students from the regions will stay there for their education, or will go to cities where they can live with relatives. Location, more than formal quality assessment, can determine institutional choice. Finally, corruption is widespread: degrees can be bought and the attestation system itself was perceived to be corrupt. Thus, then and now, families rely on word of mouth and nongovernmental evaluations to validate university quality.

\section{CONCLUSION}

Kyrgyzstan thus has specific circumstances that make the lack of formal assessment mechanisms at the national level less critical than might be the case elsewhere. Nevertheless, since among the reasons a national system seems unimportant, are that some of the stronger institutions have degrees recognized elsewhere and others are pursuing international accreditation, educators elsewhere might want to keep an eye on Kyrgyzstan. National systems of quality assessment may not be as relevant as they used to be.

\section{University Governance Reforms in Kazakhstan}

\section{Darkhan Bilyalov}

Darkhan Bilyalov is a researcher at Nazarbayev University Graduate School of Education, Astana, Kazakhstan, and PhD candidate, Pennsylvania State University, US. E-mail:dyb5296@psu.edu.

$\mathrm{N}$ ational governments worldwide are introducing western corporate governance in universities as a means to increase institutional autonomy and efficiency. Former Soviet Union countries are no exception to this global trend. 